\title{
STUDI KOMPARASI USAHA TERNAK KERBAU DI DESA UMBE KECAMATAN KEDIRI KABUPATEN LOMBOK BARAT
}

\author{
S. Rusdiana dan Riasari. G. Sianturi \\ Balai Penelitian Ternak Ciawi-Bogor PO.BOX. 221 Bogor \\ e-mail: s.rusdiana20@gmail.com
}

\begin{abstract}
The study was conducted in West Lombok, West Nusa Tenggara Province in 2014, using surveys and interviews (simple random sampling) to 21 farmers, secondary data and primary data were analyzed quantitatively, qualitatively. The purpose of this article to find out the economic analysis of business buffaloes on farmers. The results showed that, group I average ownership of buffaloes 2 tail/breeder, get a net gain of about Rp.5.850 million / year value of B/C ratio of 1.23 , the second group the average ownership of buffaloes 3 heads / breeder net profit of about Rp.9.585 million/breeder the B/C ratio of $1: 25$ and group III average kepemiikan 4 cattlelfarmer a net gain of approximately Rp.14.860 million/year value of $B / C$ ratio of 1.30. T-test results showed that the income of farmers buffalo batten groups I, II and III, there is significant and statistically that sig t-test was calculated based on the results of operations for 1-2 years for income per 2 heads, 3 heads and 4 tails probability $(0.35 \geq 0.05)$, the level of protabilitas value $>0.05$, the probability of 0.00 , the value of smaller significance $(0.00<0.05)$
\end{abstract}

Keywords: economics analysis, comparison, income, farmers.

\begin{abstract}
Abstrak: Penelitian dilakukan di kabupaten Lombok Barat, Propinsi Nusa Tenggara Barat tahun 2014, menggunakan survey dan wawancara secara (simple random sampling) terhadap 21 peternak, data sekunder dan data primer dianalisis secara kuantitatif, kualitatif. Tujuan tulisan ini untuk mengetahui analisis ekonomi usaha ternak kerbau di petani. Hasil penelitian menujukkan bahwa, kelompok I rata-rata kepemilikan ternak kerbau 2 ekor/peternak, mendapatkan keuntungan bersih sekitar Rp.5.850 juta/tahun nilai B/C ratio 1.23, kelompok II rata-rata kepemilikan ternak kerbau 3 ekor/peternak keuntungan bersih sekitar Rp.9.585 juta/peternak nilai B/C ratio 1.25 dan kelompok III rata-rata kepemiikan 4 ekor/peternak mendapat keuntungan bersih sekitar Rp. 14.860 juta/tahun nilai $\mathrm{B} / \mathrm{C}$ ratio 1.30. Hasil uji-t menunjukkan bahwa pendapatan peternak kerbau kelompok reng I, II dan III, terdapat perbedaan yang nyata dan secara statistik bahwa sig $t$-Test dihitung berdasarkan hasil usaha selama 1-2 tahun untuk pendapatan per 2 ekor, 3 ekor dan 4 ekor dengan probabilitas $(0,35 \geq 0,05)$, tingkat probabilitas nilai $\geq 0,05$, probabilitas sebesar 0,00 , nilai signifikansi lebih kecil $(0.00<0.05)$.
\end{abstract}

Kata kunci: analisis ekonomi, komparasi, pendapatan, petani.

\section{PENDAHULUAN}

Populasi ternak kerbau di Indonesia pada tahun 2013 sekitar 1.999.604 ribu ekor menurun dari tahan 2011-2012 sekitar 1.305.078-1.378.153 ribu ekor, (Statisik Pertanian Indonesia, 2012). Penurunan populasi kerbau dibeberapa wilayah di Indonesia antara lain, disebabkan terjadinya perubahan usahatani sebagai dampak kemajuan dalam bidang mekanisasi pertanian. Potensi lahan kering yang mencapai 1,6 juta ha, memang sangat potensial untuk pengembangan komoditas pertanian (Dinas Pertanian dan Kesehatan Hewan Propinsi NTB, 2013). Hampir semua petani tidak bisa dipaksakan untuk menggarap lahan kering yang dinilai 


\section{S. Rusdiana dan Riasari. G. Sianturi : Studi Komparasi Usaha Ternak ...}

lebih berisiko rugi, ketimbang menggarap lahan basah, alternatif lain dengan cara usaha ternak kerbau.

Sebagian Provinsi di Indonesia yang yang cocok dan fanatik terhadap daging kerbau seperti di Banten, NAD, Sumatra Utara, Sumatra Barat, Nusa Tenggara Barat, Kalimantan Selatan dan Sulawesi Selatan (Romjali, et al., 2012). Secara nasional wilayah NTB merupakan wilayah pengembangan ternak kerbau dan tanaman pangan, hal ini ditunjang ketersediaan daya dukung lahan pertanian yang potensial, disamping untuk menyediakan hijauan pakan ternak baik rumput atau berbagai limbah pertanian, yang dapat dimanfaatkan untuk pengembangan usaha ternak kerbau. Ternak kerbau sangat berpotensi untuk dikembangkan di Indonesia (NTB), karena kondisi geografis, ekologi, dan kesuburan lahan di beberapa wilayah Indonesia, memiliki karakteristik yang cocok untuk pengembangan ternak kerbau.

Pembangunan pertanian perlu melakukan pendekatan yang menyeluruh dan integratif dengan sub sektor peternakan dalam naungan sektor pertanian, hal ini semakin penting untuk dilakukan apabila dikaitkan dengan program ketahan pangan dalam mendukung kesejahteraan petani (Prawirodigdo dan Utoma, 2011). Tanaman pangan yang menghasilkan produksi jagung bisa diarahkan, dan bukan hanya untuk konsumsi pangan non beras, tetapi juga ketersediaan pakan, produksi jagung, padi dan lainnya, terus meningkat akan mendorong tersedianya pakan yang mencukupi, sehingga NTB tidak perlu mendatangkan pakan dari luar daerah. Diwyanto dan Handiwirawan, (2006) berpendapat bahwa, menurunnya populasi ternak kerbau di Indonesia terkait erat dengan kenyataan bahwa, para petani yang memiliki ternak kerbau, hanya sebagai pemelihara (keeper) atau pengguna (user) dan bukan sebagai peternak dalam arti produsen (breeder).

Dwiyanto et al., (2002), berpendapat bahwa, pentingnya peranan ternak kerbau di dalam sistem usahatani, semakin diperhatikan dalam dekade terakhir ini tidak hanya oleh para peneliti pertanian dan ekonomi di Indonesia, namun juga diberbagai negara Asia, dan berbagai jenis ternak telah lama digunakan dalam kegiatan usahatani di pedesaan. Andriati et al., (2007) berpendapat bahwa, disetiap wilayah pedesaan pada umumnya mempunyai potensi untuk pengembangan tanaman hortikultura, tanaman pangan, palawija dan peternakan. Kesejahteraan petani merupakan tujuan utama dalam pembangunan pertanian, sektor pertanian dan peternakan sangat besar kontribusinya, terutama dalam peningkatan perekonomian masyarakat.

Demitria et al., (2006), berpendapat bahwa, pengembangan sumber daya manusia merupakan proses untuk meningkatkan pengetahuan, kreativitas dan keterampilan, serta kemampuan dalam berusaha tani. Kusnadi (2006) berpendapat bahwa, usaha ternak kerbau merupakan suatu sistem usaha yang bersifat komplementer, usaha ternak kerbau merupakan salah satu sumber pertumbuhan baru dalam menunjang pendapatan petani disamping usaha pertanian lainnya Menurut Kusnadi (2007), pembangunan peternakan di masa mendatang masih akan di hadapkan kepada masalah sumberdaya alam, berupa pakan, meningkatnya tuntutan dan kebutuhan pembangunan ekonomi yang semakin kompleks.

Selain itu ternak-ternak kerbau dapat dikembangkan di peternakan rakyat di pedesaan dengan sarana dan prasarana yang terbatas. Kerbau merupakan jenis ternak potong, dan tergolong ternak ruminansia besar, disamping sebagai penghasil daging dan susu, juga menghasilkan kulit yang dapat dimanfaatkan untuk berbagai macam keperluan industri dan makanan kecil. Menurut Rusdiana et al., (2011), biaya produksi untuk usaha pemeliharaan ternak kerbau terpusat pada biaya produksi dan biaya tetap biaya variabel dan motif petani usaha pemeliharaan ternak kerbau adalah sebagai tabungan dan mendapatkan keuntungan yang optimal.

Ternak kerbau memiliki keunggulankeunggulan yang patut dipertimbangkan dalam pengembangan budidayanya, selain bantuan tenaga untuk mengolah lahan pertanian juga daging dan susu kerbau. Ternak kerbau sebagai salah satu kekayaan petani yang dimilikinya dan sebagai, penyangga kebutuhan hiup petani dan sewaktu-waktu dapat dijual dengan mudah, melihat permasalahan tersebut di atas maka, tujuan tulisan ini adalah untuk mengetahui analisis ekonomi secara komparasi usaha ternak kerbau pada petani, dalam rangka untuk meningkatkan pendapatan dan sekalugis dapat meninkatkan kesejahteraan petani . 


\section{METODE PENELITIAN}

\section{Waktu Penelitian}

Penelitian dilakukan di Desa Umbe Kecamatan Kediri Kabupaten Lombok Barat, Propinsi Nusa Tenggara Barat, pada tahun 2014, pemilihan lokasi penelitian dilakukan sesuai dengan kriteria luas lahan pertanian dan populasi ternak kerbau. Survey lapang dilakukan dengan melalui wawancara berstruktur terhadap 21 responden petani ternak dengan mengisi daftar pertanyaan berstruktur. Pengambilan sampel dilakukan dengan cara simple random sampling, sedang data sekunder diperoleh dari catatan dari Dinas pertanian dan Peternakan yang terkait.

Data primer diperoleh melalui hasil wawancara langsung dilapangan dengan responden yang mengacu kepada kuisioner yang telah disiapkan, sedangkan data sekunder diperoleh dari Dinas Pertanian dan Kesehatan Hewan Lombok Barat, hasil penelitan yang telah dilaporkan dan dari informasi yang terkait dengan judul penelitian, serta dari ide-ide pemikiarn sendiri, data yang terkumpul kemudian dianalisis menggunakan deskritif, kuantitatif secara analisis satitistik dan analisis ekonomi.

\section{Metoda Analisis Data}

Responden penelitian adalah petani ternak kerbau yang digolongkan ke dalam tiga kelompok I, II, dan III, berdasarkan jumlah kepemilikan ternak kerbau di petani kelompok 1 (jumlah kepemilikan rata-rata 2 ekor), kelompok II (jumlah kepemilikan rata-rata 3 ekor) dan kelompok III (jumlah kepemilikan rata-rata 4 ekor). Untuk mengetahui nilai analisis ekonomi secara komparasi usaha pemeliharaan ternak kerbau dari masing- masing kelompok I, II dan III, dihitung dengan menggunakan rumus $\mathrm{B} / \mathrm{C}$ ratio menurut Soekartawi, (1995) dan dan analisis statistik Uji-t menurut (Steel, et al., (1992), Sudjana (2000) dan Sugiyono, (2002).

\section{HASIL DAN PEMBAHASAN}

\section{Karakteristik Petani Ternak}

Secara umum tingkat pendidikan peternak di Desa Umbe Kecamatan Kediri Kabupaten Lombok Barat masih relatif rendah, masih ditemui beberapa peternak yang tidak lulus pada tingkat sekolah dasar sekitar 33,78\%, tingkat pendidikan yang terbanyak yaitu setingkat Sekolah Dasar sekitar 55.41\%, Tingkat pendidikan SMP sekitar $6.76 \%$ dan tingkat pendidikan SMA sekitar $4.25 \%$, ratarata umur peternak sekitar $45.75 \%$, mata pencaharian bertani sekitar $81 \%$ dan pengalaman bertani atau beternak sekitar $65.43 \%$. Tingkat pendidikan dan pengalaman beternak sangat berpengaruh terhadap pemahaman peternak untuk melakukan usaha ternak kerbau terhadap penerimaan teknologi,

Pada akhirnya akan berpengaruh pada adopsi teknologi yang diintroduksikan oleh lembaga atau intansi terkait, bahwa pendidikan dan pengalaman bertani dapat berpengaruh terhadap penerapan teknologi dan peningkatan pendapatan Dorian et al., (2009). Dengan adanya dukungan sarana, prasarana yang ada di petani dan pengalaman beternak yang cukup lama, maka peternak dengan sendirinya dapat memlihara ternak kerbau dan mempertahankan dengan baik, walaupun belum ada sentuhan teknologi yang diperoleh oleh petani masih secara tradisional, peternak tetap mempertahankan ternak kerbaunya.

Tabel 1. Rata-Rata Nilai Aset Ternak Kerbau di Lokasi Penelitian 2014

\begin{tabular}{lcccc}
\hline \multicolumn{1}{c}{ Nama Desa Umbe } & Ekor & Persen & $\begin{array}{c}\text { Nilai jual } \\
\text { (Rp.000) }\end{array}$ & $\begin{array}{c}\text { Nilai aset ternak kerbau } \\
\text { (Rp.000) }\end{array}$ \\
\hline Betina dewasa & 25 & 47.16 & 10.5 & 265.500 \\
Betina muda & 10 & 18.86 & 6.4 & 64,000 \\
Betina anak & 8 & 15.09 & 3.5 & 28,000 \\
Jantan dewasa & 4 & 7.54 & 13.4 & 53.600 \\
Jantan muda & 6 & 11.32 & 7.8 & 46,800 \\
Jantan anak & 6 & 11.32 & 4.3 & 25.800 \\
Jumlah & 53 & 100 & - & 483.500 \\
Rataan nilai asset kerbau/peternak & 2.52 & - & - & 23.023 \\
\hline
\end{tabular}

Sumber: Data primer diolah (2014) 


\section{Nilai Asset Ternak Kerbau}

Hasil penelitian nilai jual ternak di lokasi penelitian cukup tinggi sehingga secara tidak langsung menguntungkan peternak, dan sekaligus sebagai pemacu untuk mempertahankan keberadaan ternak kerbau. Berdasarkan hasil penelitian survey lapang pada peternak, bahwa nilai asset ternak kerbau dalam struktur kelembagaan nilai jual harga ternak kerbau terlihat pada Tabel,1.

Tabel.1. Menunjukkan bahwa dari rataan aset ternak kerbau di Desa Umbe pada kelompok peternak yang mempunyai nilai aset tertinggi adalah pada ternak betina dewasa sekitar Rp.265.500 juta. Jumlah ternak yang dipelihara oleh petani cukup tinggi. ternak kerbau mempunyai peranan sangat penting dalam sistem usahatani dan secara sosial pemilikan ternak dapat memberikan arti tersendiri bagi petani.

Kerbau sebagai salah satu kekayaan petani yang dimilikinya dan sebagai, penyangga kebutuhan hidup, serta dapat menyediakan biaya untuk kelancaran usahatani, sewaktu-waktu dapat dijual dengan mudah, sehingga dapat menekan biaya produksi usaha beternak kerbau di samping sumber pupuk organik yang dapat dikembalikan ke lahan pertanian sendiri.

\section{Peranan Ternak Kerbau di Petani}

Peternak dalam melakukan aktivitas usaha ternak kerbau masih berpola sebagai usaha sampingan, pokok, dan tabungan, karena usaha pokoknya adalah bercocok tanam atau bertani, jumlah populasi ternak kerbau di petani sekitar \pm 53 ekor atau sekitar 2,5 ekor/petani, peternak dalam kepemilikan ternak kerbaunya, disamping milik sendiri, juga ada milik orang lain, atau gaduhan, perhitungannya adalah dalam waktu $\geq 1-4$ tahun, seekor induk dapat melahirkana-3 kali beranak. Anak pertama untuk pemilik dan anak kedua untuk penggaduh dan seterusnya dengan sebutan anak gembala. Artinya ada kesepakatan antara pemiik ternak dan penggaduh, keduanya merasa diuntungkan

Tetapi sering terjadi permasalahan yang dihadapi oleh peternak adalah sistem penjualan ternak kerbau yang sedikit merugikan peternak, karena peternak tidak tahu tentang naik turunnya harga jual dan harga beli ternak kerbau pasar ternak, harga jual di peternak lebih rendah, karena sistim jual ke sesama petani ternak sendiri atau pada kelompok peternak yang memelihara kerbau secara semi intensif. Kendala lain yang sering dihadapi peternak adalah induk yang sudah dikawinkan tidak dapat bunting, mengakibatkan petani merasa rugi dan ternak yang dipelihara tidak menghasilkan keuntungan.

Hal yang lain yaitu bila musim kemarau lama pakan hijauan sangat sulit sekali, peternak tetap mempertahankan ternak walaupun dalam keadaan musim kemarau susah untuk mencari pakan, peternak tetap semangat dalam usahanya, karena peternak berpatokan dan mempunyai prinsif tersendiri bahwa, dengan memelihara satu ekor kerbau betina induk dalam jangka wakrtu 1-2 tahun, peternak akan mendapatkan keuntungan dari nilai jual hasil keturunan anak kerbau.

\section{Sistem Pemeliharaan Ternak Kerbau di Petani}

Hasil survey di lapangan menunjukkan bahwa, kelompok peternak kerbau mengandangkan ternaknya dengan sistem kandang kolonel atau bersama, dimana pada saat mengeluarkan ternak kerbau untuk digembalakan atau dipekerjakan sebagai tenaga mengolah sawah dari kandang sekitar jam 7-8 pagi, dan mengandangkan kembali ternak kerbaunya sekitar jam 4-5 sore. Semua kelompok peternak kerbau mendapat giliran untuk jaga malam, mengawasi ternak kerbau dengan sistem jaga bersama, selain alasan faktor keamanan, semua ternak dijadikan satu kandang dan tidak menggunakan peralatan bangunan, luas kandang colonel sekitar 150-200 m2 tergantung jumlah ternak kerbau yang ditampung di kandang tersebut.

Sedangkan lahan yang digunakan untuk penggembalaan ternak kebau yang ditumbuhi dengan berbagai jenis rerumputan seperti leguminose, rumput gajah, rumput raja, rumpai raket, rumput kawat, alang-alang, dan sisa limbah hasil pertanian, ketersediaan hijauan sangat tergantung pada alam terutama pada pemeliharaan ternak kerbau yang dilakukan oleh kelompok ternak karya mandiri jaya yang dilakukan secara tradisional. Ternak ketbau yang dipelihara secara ikat pindah selama siang hari petani menambahkan makan tambahan berupa rerumputan alam yang diambil dari sekitar lingkungan pemikiman penduduk 


\section{S. Rusdiana dan Riasari. G. Sianturi : Studi Komparasi Usaha Ternak ...}

sekitar, cara pemberiannya pada saat ternak kerbau terikat di bawah naungan pohon atau dalam keadaan istirahat.

\section{Sistem Kepemilikan Ternak Kerbau di Petani}

Dalam uraian ini akan dihitung berdasarkan jumlah kepemilikan ternak kerbau melalui kelompok I, II, dan kelompok III. Pada kelomok I kepemilikan ternak ternak kerbau rata-rata 2 ekor, kelompok II kepemilikan ternak kerbau rata-rata sekitar 3 ekor dan kelompok reng III kepemilikan ternak kerbau rata-rata sekitar 4 ekor. Peternak kerbau dalam pemeliharaannya masih dilakukan dengan cara tradisional, namun perternak sudah mengetahui teknologi IB kerbau dari tahun 2009. Peternak memperoleh bibit dengan membeli langsung dari pasar hewan atau dari sesama kelompok peternak, pakan yang diberikan untuk ternak kerbau baik pada peternak kelompk I, II, dan III tidak berbeda (ed libitum).

Pakan utama yang diberikan pada umumnya berupa daun-daunan dan rerumputan yang diperoleh hasil menyabit di hutan atau disekitar lingkungan, dimana ternak kerbau digembalakan di sekitar Desa Umbe. Pemberian konsentrat sangat jarang, bahkan tidak diberikan sama sekali oleh peternak, dengan alasan keuangan karena pakan hijauan mudah didapat dan tidak harus membeli.

\section{Biaya Produksi Usaha Ternak Kerbau}

Biaya tetap kelompok I, untuk pembelian peralatan sekitar Rp.500.000, pembuatan kandang 1 unit sekitar Rp.2.5 juta, sewa lahan tidak dihitungkan, karena lahan milik petani sendiri, biaya pakan dimasukan kedalam tenaga kerja kelaurga, untuk mencari pakan dan memeliharanya dihitung berdasarkan jumlah kerbau yang dipelihara 2 ekor dengan nilai biaya yang dikeluarkan sekitar Rp.5.000/ekor/hari/tahun sekitar Rp.3.6 juta/tahun. Biaya variabel untuk nilai pembelian bibit I (1 ekor jantan dan1 betina), dengan perkiraan rata-rata umur sekitar 1,6 tahun, perkiraan rata-rata bobot badan hidup sekitar $\pm 250 \mathrm{~kg} / \mathrm{ekor}$ ) dan perkiraan harga sebesar Rp.21 juta.

Biaya tetap kelompok II, untuk pembelian peralatan sekitar Rp.600.000, pembuatan kandang 1 unit sekitar Rp.3.5 juta, sewa lahan tidak dihitungkan, karena lahan milik petani sendiri, dan biaya pakan dimasukan kedalam tenaga kerja petani. Untuk biaya mencari pakan dan memelihara dihitung berdasarkan jumlah kerbau yang dipelihara 3 ekor dengan nilai biaya yang harus dikeluarkan sekitar Rp.5.000/ekor/hari/tahun sekitar Rp.5.4 juta/tahun, biaya variabel untuk nilai pembelian bibit II (1 ekor janta dan 2 ekor betina), dengan perkiraan rata-rata umur sekitar 1.6 tahun, perkiraan rata-rata bobot badan hidup sekitar $\pm 250 \mathrm{~kg} / \mathrm{ekor})$ dan perkiraan harga sebesar Rp.31 juta.

Biaya tetap kelompok reng III, untuk pembelian peralatan sekitar Rp.700.000, pembuatan kandang 1 unit sekitar Rp.4.5 juta, sewa lahan tidak dihitungkan, karena lahan milik petani sendiri, dan biaya pakan dimasukan kedalam tenaga kerja kelaurga, untuk mencari pakan dan memeliharanya dihitung berdasarkan jumlah kerbau yang dipelihara 4 ekor dengan nilai biaya yang harus dikeluarkan sekitar Rp.5.000/ekor/hari/tahun sekitar Rp.7.2 juta/tahun. Biaya variabel untuk pembelian bibit III (1 ekor jantan dan 3 betina), dengan perkiraan rata-rata umur sekitar 1.6 tahun, perkiraan rata-rata bobot badan hidup sekitar $\pm 250 \mathrm{~kg} /$ ekor) dan pekiraan harga sebesar Rp.41 juta.

Berdasarkan biaya produksi dan biaya variabel selama usaha berlangsung, sehingga akan terlihat hasil keuntungan yang di peroleh pada masing-masing kelompok I, II dan III, semua biaya yang telah dikeluarkan selama usaha berlangsung. Hasil keuntungan dari maisng-masning kelompok reng I, nilai jual 1 ekor anak rata-rata umur sekitar 5 bulan Rp.4.5 juta, dan nilai jual 2 ekor induk dan jantn dewasa sekitar Rp.31.2 juta, kelompok II, nilai jual 2 ekor anak sekitar Rp.8.5 juta dan nilai jual 3 ekor iduk dan jatan dewasa sekitar Rp.47 juta, nilai jual 3 ekor anak sekitar Rp.13.5 juta, dan nilai jual 4 ekor, induk dan jantan dewasa sekitar Rp.64.2 juta terlihat pada Tabel.2.

Tabel 2. menunjukkan bahwa biaya tenaga kerja keluarga peternak untuk usaha memelihara ternak kerbau, merupakan biaya terbesar yaitu pada kelompok reng III, dilihat dari jumlah ternak yang dipelihara lebih banyak, pendapatan yang diperoleh dari masing-masing kelompok I sekitar Rp.31.20 juta /tahun nilai $\mathrm{B} / \mathrm{C}$ ratio 1,2 , II sekitar Rp.47.00 juta/tahun nilai B/C ratio 1.25 dan III sekitar Rp.64.20 juta/tahun nilai $\mathrm{B} / \mathrm{C}$ ratio 1.30 . 
S. Rusdiana dan Riasari. G. Sianturi : Studi Komparasi Usaha Ternak ...

Tabel.2. Biaya Produksi Rata-Rata Per Tahun kelompok I, II dan III di Peternak

\begin{tabular}{|c|c|c|c|c|c|c|}
\hline \multirow[t]{2}{*}{ Uraian } & \multicolumn{2}{|c|}{ Kelompok I } & \multicolumn{2}{|c|}{ Kelompok II } & \multicolumn{2}{|c|}{ Kelompok III } \\
\hline & Rp.000 & $\%$ & Rp.000 & $\%$ & Rp.000 & $\%$ \\
\hline \multicolumn{7}{|l|}{ 1.Biaya Tetap } \\
\hline -biaya penyusuta kandang & 500 & 83 & 700 & 0,84 & 900 & 65 \\
\hline -biaya penyusutan peralatan & 100 & 16 & 120 & 0,15 & 140 & 13 \\
\hline Jumah & 600 & 100 & 820 & 100 & 1.04 & 100 \\
\hline \multicolumn{7}{|l|}{ 2.Biaya variable } \\
\hline -pembelian bibit betina & 10.0 & 40 & 20.0 & 55 & 30.0 & 62 \\
\hline -pembelian bibit jantan & 11.0 & 44 & 11.0 & 30 & 11.0 & 22 \\
\hline -obat-obatan-paket & 50 & 0.20 & 75 & 0,21 & 100 & 0.21 \\
\hline -tenaga kerja keluarga & 3.6 & 0.15 & 5.4 & 15 & 7.2 & 15 \\
\hline -biaya pakan & - & - & - & & - & \\
\hline Jumlah & 24.65 & - & 36.475 & - & 48,3 & - \\
\hline Jumlah biaya tetap + variabel & 25.350 & - & 37.415 & - & 49.30 & \\
\hline \multicolumn{7}{|l|}{ 3.Pendapatan } \\
\hline $\begin{array}{l}\text {-nilai jual anak, betina dan } \\
\text { jantan }\end{array}$ & 4.5 & 15 & 8.5 & 18 & 13.50 & 21 \\
\hline -nilai jual betina induk & 12.20 & 39 & 24.20 & 51 & 36.30 & 56 \\
\hline -nilai jual jantan dewasa & 14.50 & 46 & 14.30 & 30 & 14.40 & 22 \\
\hline Jumah pendapatan & 31.20 & - & 47.00 & - & 64.200 & - \\
\hline Pendapatan bersih & 5.850 & - & 9.585 & - & 14.860 & - \\
\hline $\mathrm{B} / \mathrm{C}$ & 1.23 & - & 1.25 & - & 1.30 & - \\
\hline
\end{tabular}

Sumber: Data primer diolah (2014)

Tabel 3. Hasil Uji-t Keuntungan Analisis Komparatif Usaha Ternak Kerbau

\begin{tabular}{|c|c|c|c|c|c|c|c|c|}
\hline \multirow[t]{3}{*}{ Peubah } & \multicolumn{5}{|c|}{ Paired Differences } & \multirow{3}{*}{$\mathrm{T}$} & \multirow{3}{*}{$\begin{array}{l}\mathrm{D} \\
\mathrm{f}\end{array}$} & \multirow{3}{*}{$\begin{array}{c}\text { Sig. } \\
\text { (2-tailed) }\end{array}$} \\
\hline & \multirow[t]{2}{*}{ Mean } & \multirow{2}{*}{$\begin{array}{c}\text { Std. } \\
\text { Deviation }\end{array}$} & \multirow{2}{*}{$\begin{array}{l}\text { Std. } \\
\text { Error } \\
\text { Mean }\end{array}$} & \multicolumn{2}{|c|}{$\begin{array}{c}95 \% \text { Confidence Interval } \\
\text { of the Difference }\end{array}$} & & & \\
\hline & & & & Lower & Upper & & & \\
\hline Kelompok reng I & 835 & 1.55 & 0.21 & 3.44 & 835 & 5.71 & 21 & .000 \\
\hline Kelompok reng II & 1.308 & 1.67 & 0.23 & 5.67 & 1.308 & 9.58 & 21 & .000 \\
\hline Kelompok reng III & 2.122 & 1.89 & 0.27 & 8.87 & 2.122 & 14,82 & 21 & .000 \\
\hline
\end{tabular}

Sumber: Data primer diolah (2014)

Nilai yang diperoleh peternak paling tinggi dinominasi oleh kelompok reng III, nilai ekonomi secara komparasi dari ketiga kelompok I ,II dan III, ternyata yang lebih efisien dan efektif adalah dengan jumlah usaha pemeliharaan ternak kerbau sekitar $\geq 4$ ekor/peternak pada kelompok reng III.

Penerimaan diperhitungkan merupakan nilai jual ternak kerbau anak, betina induk dan jantan dewasa per tahun, kelompok I dengan rata-rata kepemilikan ternak kerbau 2 ekor peternak mendapat keuntungan bersih sekitar Rp.5.85 juta /tahun, kelompok II dengan ratarata kepemilikan terak kerbau 3 ekor peternak mendapat keuntungan sekitar Rp.9.585 juta/peternak dan kelompok III dengan rata-rata kepemiikan 4 ekor, keuntungan peternak sekitar Rp.14.860 juta/tahun.

\section{Analisis Uji t, Komparatif Kelompok Reng I, II dan III, Ternak Kerbau}

Untuk melihat komparatif antara kelompok I, II dan III dari usaha ternak kerbau, dengan analisis Uji-t, untuk membandingkan ke tiga variabel tersebut sama atau berbeda, maka dengan menggunakan hasil analisis $\mathrm{Uji} t$ terlihat pada Tabel.3

Tabel 3 menunjukkan bahwa, hasil analisis uji-t dari kesamaan rataan pada tingkat kepercayaan 95\%, menunjukkan bahwa ada perbedaan yang signifikan antara rata-rata pendapatan dari masing-masing kelompok I, II dan III, hal ini ditandakan dengan nilai 
signifikansi (Sig.) sebesar 0.000, yang lebih kecil dari nilai 0.05 .

Berdasarkan pada uji-t menunjukkan bahwa pendapatan peternak kerbau kelompok reng I, II dan III terdapat perbedaan yang nyata dan secara statistik bahwa sig $t$-Test dihitung berdasarkan hasil usaha selama 1-2 tahun untuk pendapatan 2 ekor, 3 ekor dan 4 ekor dengan probabilitas $(0.35 \geq 0.05)$, dengan tingkat probabilitas nilai $\geq 0.05$, probabilitas sebesar 0.00. Nilai signifikansi lebih kecil, $(0.00 \leq 0.05)$, terdapat perbedaan nyata antara antara kelompok I.

\section{KESIMPULAN}

Usaha ternak kerbau pada kelompok reng III dengan rata-rata pemeliharaan sekitar 4 ekor/peternak, ternyata mendapatkan keuntungan yang lebih tinggi sekitar Rp.14.860 juta/tahun nilai $\mathrm{B} / \mathrm{C}$ ratino 1,30 , dibandingkan dengan kelompok I dengan kepemilikan 2 ekor. Peternak dan kelompok II dengan kepemilikan 3 ekor/peternak keuntungan yang diperoleh sekitar Rp. 9.850 juta/tahun dan Rp.9.55 juta/tahun, nilai $\mathrm{B} / \mathrm{C}$ ratio 1.23 dan 1.25. Ternyata kelompok III dengan kepemilikan 4 ekor ternak kerbau sanget efektif dan efisien baik dalam pengeluaran biaya produksi maupun biaya variabel.

Keuntungan yang diperoleh peternak tergantung jumlah ternak kerbau yang dipelihara, usaha pemeliharaan ternak kerbau sekitar $\geq 4$ ekor/peternak, sangat ekonomis, jumlah biaya tetap dan biaya variabel hampir sama dengan jumlah pemeliharaan 2-3 ekor/peternak. Nilai signifikansi lebih kecil dari $(0.00<0,05)$, berarti terdapat perbedaan keuntungan sangat nyata antara kelompok I, II, dan III.

\section{DAFTAR PUSTAKA}

Andriati dan Wayan Sudana. 2007. Keragaman dan Analisis Finansial Usahatani Padi (Kasus Desa Primatani, Kabupaten Karawang, Jawa Barat). Balai Besar Pengkajian dan Pengembangan Teknologi Pertanian Bogor, Jurnal Pengkajian dan Pengembangan Teknologi Pertanian Vol. 10 No. 2, Juli 2007 Hal. 106-118.
Dwiyanto.K., Bambang, R.Prawiradiputra dan Darwinsyah. L.2002. Integrasi TanamanTernak Dalam Pengembangan Agribisnis yang Berdaya Saing, Berkelanjutan dan Berkerakyatan. Wartazoa, Buletin Ilmu Peternakan Indonesia Vol. 12 No. 1 tahun 2002, hlm.1-8

Diwyanto, K. dan E. Handiwirawan, 2006. Strategi Pengembangan Ternak Kerbau : Aspek Penjaringan dan Distribusi. Prosiding Seminar Lokakarya Nasional Pusat Penelitian dan Pengembangan Peternakan Bogor, Sumbawa 4-5 Agustus 2006. hal. 3 - 12.

Demitria.D., Harianto, Sjafri.M., dan Nunung. 2006. Peran Pembangunan Sumberdaya Manusia dalam Peningkatan Pendapatan Rumah Tangga Petani di Daerah Istimewa Yogyakarta. Forum Pascasarjana. IPB. Vol.33. No.3. Juli 2010. hal. 155-164.

Dorian, S. dan I. Istina. 2009. Motivasi petani terhadap peternakan di Kabupaten Kampar (Studi Kasus Prima Tani Kebupaten Kampar). Pros. Seminar Nasional Membangun Sistem Inovasi di Pedesaan. 15-16 Oktober 2009. BBP2TP, Bogor. hlm. 698-704

Direktorat Jenderal Peternakan dan Kesehatan Hewan Jakarta. 2011. Pertumbuhan dan produksi ternak ruminanasia besar dan kecil. Direktorat Jenderal Peternakan dan Kesehatan Hewan, Kementerian Pertanian, Jakarta

Dinas Pertanian dan Kesehatan Hewan Kabupaten Lombok Barat, Propinsi Nusa Tenggara Barat, 2013.dalam data Statistik Pertanian

Kusnadi. U., B. Setiadi dan E. Juarini. 2006. Analisis Potensi Wilayah Peternakan di Pulau Sumatera. Prosiding Seminar Nasional Peternakan, Balai Pengkajian Teknologi Pertanian Sumatera Barat, Kerjasama, Fakultas Peternakan Universitas Andalas Padang Mangatas, Dinas Peternakan Provinsi Sumatera Barat, Balai Besar Pengkajian 
Pengembangan Teknologi Pertanian, Badan Penelitian Dan Pengembangan Pertanian, Padang 11-12 September 2006. Hal. 32-41.

Kusnadi.U. 2007. Kelayakan Usaha Kerbau Untuk Penghasil Bibit.Dan Daging Dibeberapa Agroekosistem Prosiding Seminar Nasional Teknologi Peternakan dan Veteriner. Puslitbang Peternakan, Bogor, 13-14 Agustus 2008, hal. 186192.

Rusdiana.S., I.Gusti A. Mahendri dan Chalid Talib. 2011. Pendapatan Usaha Ternak Kerbau di Kecamatan Gunung Sindur Bogor Jawa Barat. Prosiding Seminar Nasional Kerbau Bekerjasama dengan Dinas Peternakan Proppinsi Kalimantan Timur, Dinas Peternakan Kotamadya Samarinda, Direktorat Jendeal, Direktorat Jenderal Peternakan dan Kesehatan Hewan, Pusat Penelitian dan Pengembangan Peternakan Bogor, Samarinda 21-22 Juni 2011. hal. 152-158

Prawirodigdo.S., dan B. Utomo. 2011. Peluang Pengembangan Ternak Kerbau Rawa Di Kantong Bibit Sapi Potong Lokal, Grobogan Ditinjau Dari Aspek Ketersediaan Pakan.Prosiding Seminar Nasional, Puslitbangnak bekerjsama dengan Dinas Peternakan Nasional Lebak, Lebak Direktorat Perbibitan,
Direktorat Jenderal Peternakan, LebakBanten 2-4 Nopember 2010, hal, 174181.

Romjali,E.. Edwardi, Dan S. Rusdiana. 2012. Peluang Dan Potensi Usaha Ternak Kerbau Di Sumatera Barat. Prosiding Seminar Naisonal, Dias Peternakan Sumatera Barat. Pusat Penelitian dan Pengembangan Peternaka, Sumatera Barat Oktober 2012, Hal. 63-69

Steel, G.D. Robert and James H. Torrie . 1992. Principles and Procedures of Statistics, Biometrical Approach $2^{\text {nd }}$ Edition McGraw-Hill Book Company, New York. USA, pp. 102-109.

Soekarwati.1995. Ilmu Usahatani dan Penelitian untuk Pengembangan Petani Kecil UI Press, Jakarta. 1995.

Sudjana, 2000. Metoda Statistika, Edisi ke 5, dilindungi oleh hak cipta CV Tarsito, Bandung 2000.

Sugiyono. 2002. Statistika untuk Penelitian. Dilindungi oleh hak cipta CV. Alfabeta, Bandung 2002.

Statistik Pertanian, Departemen Pertanian Republik Indonesia Jakarta. 2012. Populasi Ternak Ternak Sapi dan Kerbau untuk Kecukupan Daging Jakarta. 